\title{
Human Error Analysis Technique and Its Application to Marine Accidents
}

\author{
Seong $\mathrm{Na}^{*} \cdot$ Hong-tae Kim ${ }^{*} \cdot$ Hye-jin Kim*** Wook-hyun Ha*** \\ *,**,*** Researcher, Maritime \& Ocean Engineering Research Institute, KORDI, Daejeon 305-343, Korea \\ + Principal Researcher, Maritime \& Ocean Engineering Research Institute, KORDI, Daejeon 305-343, Korea
}

\begin{abstract}
The management of safety at sea is based on a set of internationally accepted regulations and codes, governing or guiding the design and operation of ships. The regulations most directly concerned with human safety and protection of the environment are, in general, agreed internationally through the International Maritime Organization(IMO). IMO has continuously dealt with safety problems and, recognized that the human element is a key factor in both safety and pollution prevention issues(IMO, 2010). This paper proposes a human error analysis methodology which is based on the human error taxonomy and theories (SHELL model, GEMS model and etc.) that were discussed in the IMO guidelines for the investigation of human factors in marine casualties and incidents. In this paper, a cognitive process model, a human error analysis technique and a marine accident causal chains focused on human factors are discussed, and towing vessel collision accidents are analyzed as a case study in order to examine the applicability of the human error analysis technique to marine accidents. Also human errors related to those towing vessel collision accidents and their underlying factors are discussed in detail.
\end{abstract}

Key words : human element, human error analysis, SHELL model, GEMS model, cognitive process model

\section{Introduction}

Traditionally, the shipping industry has focused on the hardware factors, such as ship's structure and equipment systems in order to make ships safer and more efficient. As a result, today's marine engineering systems are technologically advanced and highly reliable. However, the rates of marine accidents are still high, raising safety and environmental concerns from maritime interests(HFW, 2002).

Nationally and internationally reported statistics on marine accidents show that $80 \%$ or more of all marine accidents are caused fully or in part by human error. According to the statistics of marine accident causes from Korean Maritime Safety Tribunal(KMST), operating errors are implicated in $78.7 \%$ of all marine accidents that occurred from 2002 to 2006. In the case of the collision accidents, about 95\% of all collision accidents are caused by operating errors, and those human error related collision accidents are mostly caused by failure of maintaining proper lookout and breach of the regulations for preventing collision(KMST, 2009b).

It is clear from the above that the issue of reducing the rates of marine accidents will not be resolved by addressing engineering alone because anywhere in the maritime systems on board ship and ashore, there always is a human controlling the system. Furthermore, if a system with new technology is installed onboard ship, it even creates a need for improvement of the operator's qualification and knowledge. In this regard, the International Maritime Organization(IMO) stated that the study of human factors would be an important focus for improving maritime safety, and in the 1990s, started to focus on introducing new regulations such as the International Safety Management(ISM) Code and the revised Standards for Training, Certification and Watchkeeping for Seafarers(STCW) that incorporated a human element viewpoint(Michelle Grech et al. 2008). In recent years, the IMO adopted the amendments to the Code for the Investigation of Marine Casualties and Incidents incorporating the guidelines for the investigation of human factors in marine casualties and incidents. Also the IMO has recently adopted the Consolidated text of the Guidelines for Formal Safety Assessment(FSA) for use in the IMO rule-making process incorporating the human element into the FSA process using Human Reliability Analysis(HRA).

Table 1 shows an investigation process that provides a step-by-step systematic approach for use in the investigation of human factors and also shows how the HRA techniques fits into the FSA process(IMO, 2000; IMO, 2007).

\footnotetext{
* ras4002@moeri.re.kr, (042)866-3658

† Corresponding author: kht@moeri.re.kr, 042)866-3643

** hjk@moeri.re.kr, (042)866-3649

*** hawookhyun@moeri.re.kr, (042)866-3643
} 
Table 1 Human factor investigation process and incorporation of HRA into the FSA pro cess(IMO)

\begin{tabular}{|c|c|c|}
\hline Investigation Process & FSA Process & $\begin{array}{l}\text { Task required to } \\
\text { incorporate HRA }\end{array}$ \\
\hline \multirow{5}{*}{$\begin{array}{l}\text { 1. Collect occurrence } \\
\text { data } \\
\text { 2. Determine occurrence } \\
\text { sequence } \\
\text { 3. Identify unsafe acts } \\
\text { or decisions and } \\
\text { unsafe conditions } \\
\text { and then for each } \\
\text { unsafe acts or } \\
\text { decision } \\
\text { 4. Identify the error } \\
\text { type or violation } \\
\text { 5. Identify underlying } \\
\text { factors } \\
\text { 6. Identify potential } \\
\text { safety problems } \\
\text { and safety actions }\end{array}$} & $\begin{array}{c}\text { Step 1 } \\
\text { Hazard } \\
\text { Identification }\end{array}$ & $\begin{array}{l}\text { Identification of } \\
\text { key human tasks }\end{array}$ \\
\hline & $\begin{array}{c}\text { Step } 2 \\
\text { Risk Analysis }\end{array}$ & $\begin{array}{l}\text { Detailed task } \\
\text { analysis } \\
\text { Human error } \\
\text { analysis } \\
\text { Human error } \\
\text { quantification }\end{array}$ \\
\hline & $\begin{array}{c}\text { Step } 3 \\
\text { Risk Control } \\
\text { Options }\end{array}$ & $\begin{array}{l}\text { Risk Control } \\
\text { options for human } \\
\text { element }\end{array}$ \\
\hline & $\begin{array}{c}\text { Step } 4 \\
\text { Cost Benefit } \\
\text { Assessment }\end{array}$ & \\
\hline & $\begin{array}{c}\text { Step } 5 \\
\text { Recommendat } \\
\text { ions for } \\
\text { Decision } \\
\text { Making }\end{array}$ & \\
\hline
\end{tabular}

This paper proposes a human error analysis method that contains a cognitive process model, a human error analysis technique and a marine accident causal chains focused on human factors. In this paper, the cognitive process model that can be used as a tool to identify unsafe acts, decisions or conditions is discussed in detail, and 18 towing vessel collision accidents are analyzed to identify related unsafe acts. Then the human error analysis technique which is based on the well-established human error frameworks such as SHELL model and Reason's Generic Error Modeling Systems(GEMS) framework is used to identify underlying factors that cause those identified unsafe acts to occur. Lastly, in order to derive the optimum safety barriers, the marine accident causal chains are used.

\section{Human cognition onboard ship}

\subsection{Cognitive process onboard ship}

Before any attempt to identify and analyze potential human error is made, the cognitive process on human behavior should be examined first. Fig. 1 shows a cognitive process that consists of six elements: Pre-task Planning; Risk perception; Situation awareness; Planning \& decision-making; Action execution; and Execution Analysis. This cognitive process is based on the cognitive framework for TRACEr(technique for the retrospective and predictive analysis of cognitive errors) in Air Traffic Control(ATC) which comprises: Perception; Memory; Judgment, planning and decision-making; and Action execution(Shorrock, 2002).

In regard to the human cognitive process onboard ship, it can be seen that those cognitive elements, especially 'Risk perception', 'Situation awareness', 'Planning \& decision making' and 'Action execution', generally occur in a cyclic manner. For example, if a vessel is approaching and the compass bearing of the approaching vessel does not appreciably change, the Officer Of the Watch(OOW) will perceive the risk of collision and judge the situation considering the prevailing circumstances and conditions such as traffic density, ship's position etc.. Then the OOW will make a plan of when and how to take action to avoid collision and finally the OOW will take action to avoid collision when appropriate.

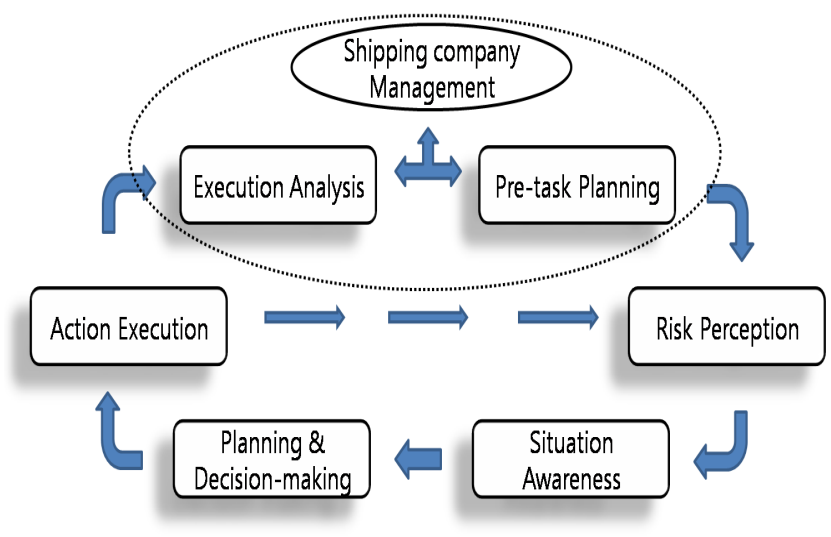

Fig. 1 Cognitive process model

\subsection{Cognitive task analysis}

In order to find out unsafe acts and unsafe decisions or conditions, the operator's behavior should be analyzed considering the following stages:

'Pre-task planning' - plan for the task(including voyage planning) considering ship's state, crew member's ability, task features(task complexity and task load, unfamiliarity of the task, ambiguity of the task goal, etc.), external factors, etc.; 'Risk perception' - detect dangerous situations or events that could affect pre-planned normal tasks; 'Situation awareness' - comprehend the dangerous situation causing a threat to the safety of the vessel based on the operator's ability and experience; 'Planning \& Decision-making' identify all possible actions that could avoid dangerous situation and choose the most appropriate one; 'Action execution' - The most appropriate actions must be initiated and performed at the appropriate place and time, and periodic checks should be made to ensure that the action sequence is 
proceeding as intended; and 'Execution analysis' - analyze the operator's action that had been performed and the dangerous situations or events that had occurred. In this execution analysis stage, those human error analysis techniques can be used to get more efficient result.

\section{Human error analysis technique}

\subsection{A proposed human error analysis technique}

A significant number of human error analysis techniques such as Human Factors Analysis and Classification System(HFACS), Rail Accident Investigation Branch(RAIB), Human Performance Enhancement System(HPES), Cognitive Reliability and Error Analysis Method(CREAM) etc. have been developed in other industries such as the chemical process plants, aerospace industry and nuclear power process industry etc.. However, it will be inefficient to apply those human error analysis techniques directly to the marine accidents. Therefore, this paper tries to propose a human error analysis technique that would be simple to use and could reflect the characteristics of marine accidents. The proposed human error analysis technique adopted the human factor classification system and the GEMS Framework which were discussed in the code for the investigation of human factors in marine casualties and incidents that was introduced by IMO, and can be used as a tool to identify underlying factors that cause unsafe acts to occur(see Fig. 2 below). The human factor classification system in the IMO guidelines for the investigation code of human factors classifies those human factors into six groups: People Factors; Ship Factors; Working and Living Conditions; Organization on board; Shore-side Management; and External Influences and Environment(IMO, 2000). The GEMS Framework which is an error classification scheme developed by Reason describes four potential error/violation categories: skill-based slip, skill-based lapse, rule-based and knowledge-based mistake, and violation(Reason, 1990; IMO, 2000).

As shown in Fig. 2, the human error analysis technique in this study consists of three levels of failure: Unsafe Acts; Preconditions for Unsafe Acts(ship-related); and Preconditions for Unsafe Acts(shipping company-related).

In terms of human error, those actions immediately linked to the accident are typically called 'unsafe acts'(HFW, 2002). The unsafe acts of crew onboard ship can be loosely classified into two categories: Unintentional action; and Intentional action. Unintentional actions are actions that do not go as planned, and intentional actions, on the other hand, are actions that are carried out as planned but the actions are inappropriate. Then those unsafe acts are divided into four potential error/violation categories, i.e., slip, lapse, mistake and violation. A slip is an unintentional action where the failure involves attention. A lapse is an unintentional action where the failure involves memory. A mistake is an intentional action, but there is no deliberate decision to act against a rule or plan. A violation is a planning failure where a deliberate decision to act against a rule or plan has been made(IMO, 2000).



Fig. 2 Human error analysis technique diagram

Preconditions for unsafe acts(ship-related) are divided into three categories: External Factors; People Factors; and Ship Factors. External Factors include environment influences and regulatory influences. People Factors include mental states, physical states and crew competency \& readiness. Lastly, Ship Factors include organization on board, technical influences and working \& living conditions. Some examples of those underlying factors are as follows:

(1) External Factors

- Environment: Weather conditions, Sea state, Port and transit conditions(VTS, Pilot, etc.), Traffic density, Ice conditions etc.

- Regulatory Influences: Special rules made by an appropriate local authority, International regulations and codes, Survey and inspections etc.;

(2) People Factors

- Mental States: Emotional state, Complacency, Distraction, Haste/Panic etc.

- Physical States: Medical fitness, Drugs and Alcohol, Fatigue etc. 
- Crew Competency \& Readiness: Lack of experience, Poorly qualified, etc.; and

(3) Ship Factors

- Organization on Board: Composition of the crew(nationality, competence), Manning level, Workload, Complexity of tasks, On-board management and supervision, Planning(voyage, cargo, maintenance) etc.

- Technical Influences: Design, State of maintenance, Equipment(availability, reliability), Cargo characteristics (including securing, handling and care) etc.

- Working \& Living Conditions: Level of automation, Adequacy of living conditions, Opportunities for recreation and rest, Adequacy of food, Level of ship motion, vibrations, heat and noise etc..

Preconditions for unsafe acts(shipping company-related) include Inadequate Management, Inappropriate Operations and the company's supervisory violations.

The aims of using the human error analysis technique proposed in this paper is to identify underlying factors that have a direct or indirect impact on occurrence of the unsafe acts that were identified by the cognitive process model considering each one of those categories in the human error analysis diagram and to prioritize them in order of their criticality so that those underlying factors that may require more attention to reduce the probability of occurrence of human error can be identified. For example, according to the results of 18 accidents of towing vessel collision illustrated in Fig. 3, 'Fail to maintain proper lookout' was identified as an unsafe act, then the ship-related underlying factors that cause the unsafe act to occur were identified. Those identified underlying factors are as follows: People factors Mental states - 'Complacency' \& 'Conceit'; People factors Physical states - 'Fatigue'; People factors - Crew competency - 'Misunderstanding of situation'; and Ship factors - Organization onboard - 'Slack supervision by master'.

\subsection{Effect levels}

Fig. 3 shows those identified unsafe acts that cause towing vessel collision accidents to occur and their underlying factors, and also shows the relationship between those human factors(unsafe acts and their underlying factors) and their Effect Levels(EL)(Jong and Park 1998).

In general, it is hard to collect empirical data from industry. There is often inadequate data or imprecise information available when carrying out human error analysis(Ren et al., 2008). When data are not available, expert judgment, physical models, simulations and analytical models may be used to achieve valuable results. There has also been a lack of human error data including the primary causes, underlying factors and latent factors associated with a casualty. Thus, this study used expert judgements rather

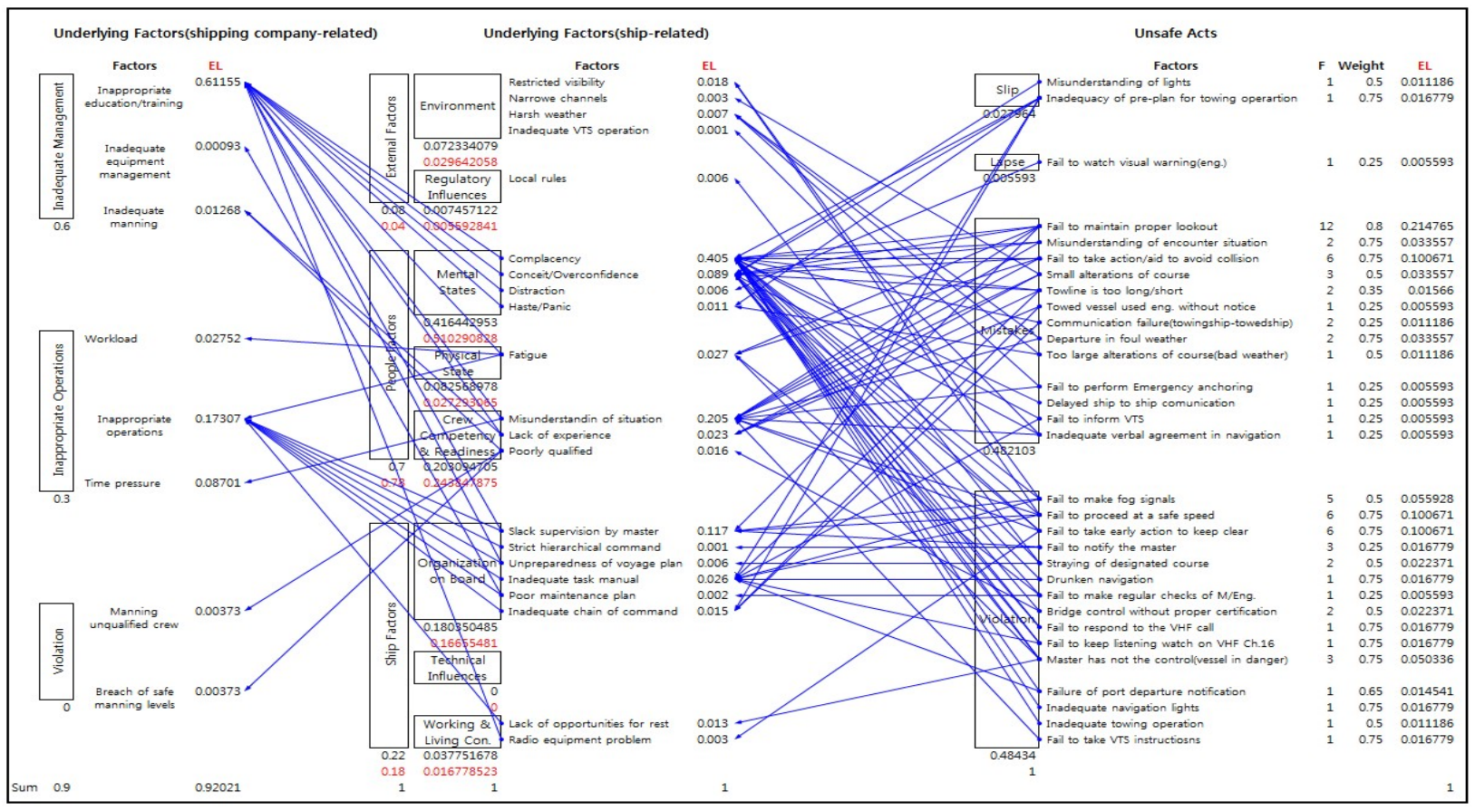

Fig. 3 The results of towing vessel collision accidents(18 accidents) analysis 


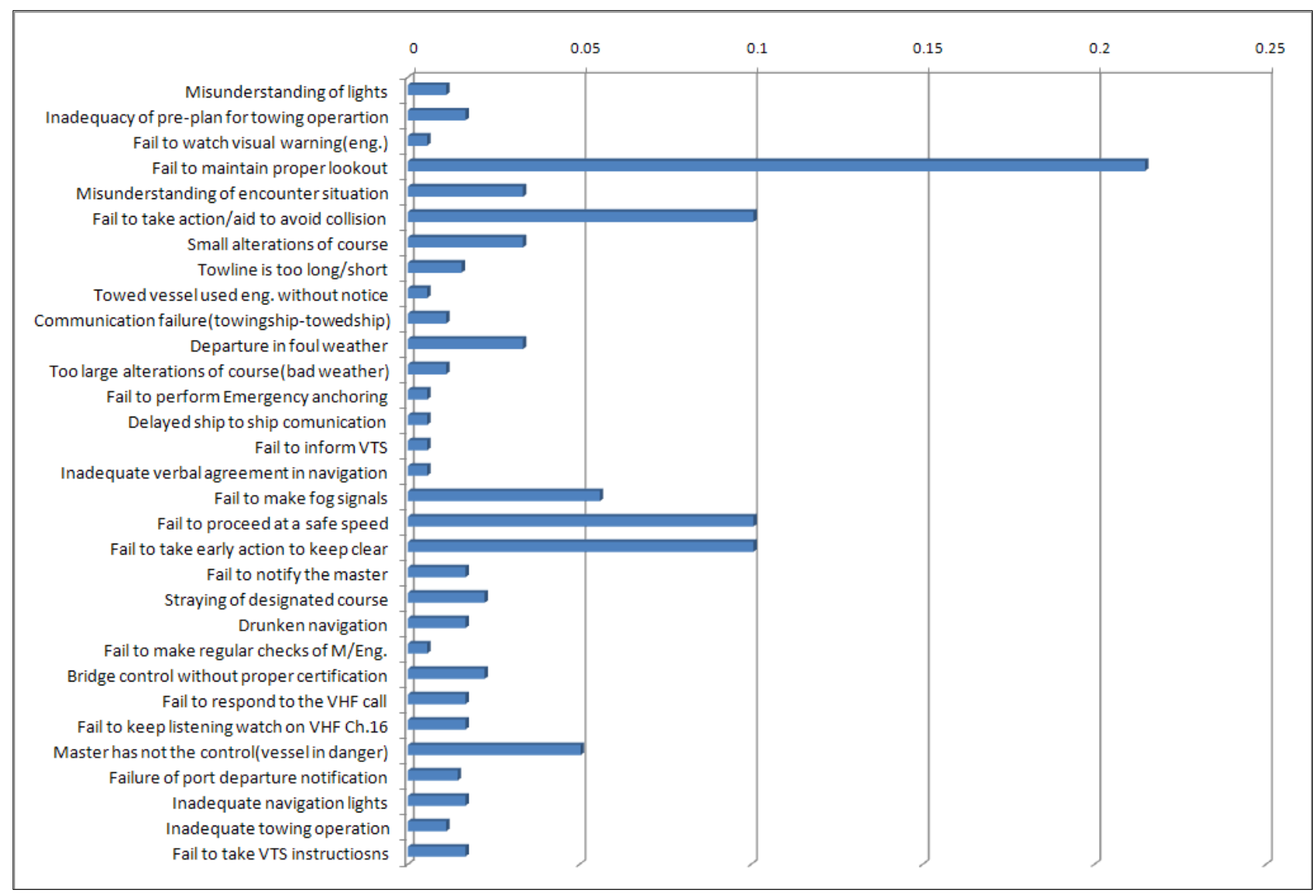

Fig. 4 Effect levels of unsafe acts

than trying to use the human error probabilities.

In order to identify human factors that may require more attention, this human error analysis technique provides Effect $\operatorname{Levels}\left(\sum=1\right.$, Effective level(EL) $\left.=\mathrm{F} \times \mathrm{W}\right)$ of all unsafe acts and underlying factors, using 'Frequency $(\mathrm{F})$ ' of unsafe acts derived from written accident reports and 'Weight(W)' of unsafe acts derived from expert judgments based on Table 2(Jong, and Park, 1998). Also, the human error analysis technique uses the relative evaluation rather than using absolute evaluation. In this study, those unsafe acts were identified from written accident reports from Korean Maritime Safety Tribunal(KMST, 2008; KMST, 2009a). A brief description of the risk-weight of unsafe acts is shown in Table 2.

The results of 18 towing vessel collision accidents are illustrated in Figures 4, 5 and 6. Fig. 4 shows the Effect Levels of those identified unsafe acts. It can be seen that the unsafe act 'Fail to maintain proper lookout' has the highest Effect Level with the rate of 0.215 and the unsafe acts such as 'Fail to take action/aid to avoid collision', 'Fail to proceed at a safe speed' and 'Fail to take early action to keep clear' are scored next with the rate of 0.10 .
Table 2 Risk-Weight of unsafe acts

\begin{tabular}{|c|l|}
\hline Weight & \multicolumn{1}{|c|}{ description } \\
\hline 1.00 & $\begin{array}{l}\text { The factor that is certain and indisputable. } \\
\text { if the factor is removed or replaced, the } \\
\text { accident will probably be } \\
\text { prevented }(90 \sim 100 \%) \text {. }\end{array}$ \\
\hline 0.75 & $\begin{array}{l}\text { The factor that definitely has a significant } \\
\text { effect on the accident. }\end{array}$ \\
\hline 0.50 & $\begin{array}{l}\text { The factor that has a considerable effect on } \\
\text { the accident. Although the factor is removed } \\
\text { or replaced, the accident will not be } \\
\text { prevented. }\end{array}$ \\
\hline 0.00 & $\begin{array}{l}\text { The factor that has a somewhat effect on } \\
\text { the accident. }\end{array}$ \\
\hline \\
$\begin{array}{l}\text { The factor that has an indefinite effect on } \\
\text { the accident. An insignificant factor. }\end{array}$ \\
\hline
\end{tabular}

Fig. 5 and Fig. 6 show the Effect Levels of ship related underlying factors and shipping company related underlying factors respectively. In regard to the underlying factors occurred onboard ship, 'operator's Complacency' has the highest rate of $0.405 \mathrm{EL}$, followed by 'Misunderstanding of dangerous situation' and 'Slack supervision by master' with EL of 0.205 and 0.117 respectively. According to the results of the shipping company related underlying factors, 'Inappropriate education/training' has the highest rate of $0.612 \mathrm{EL}$. 


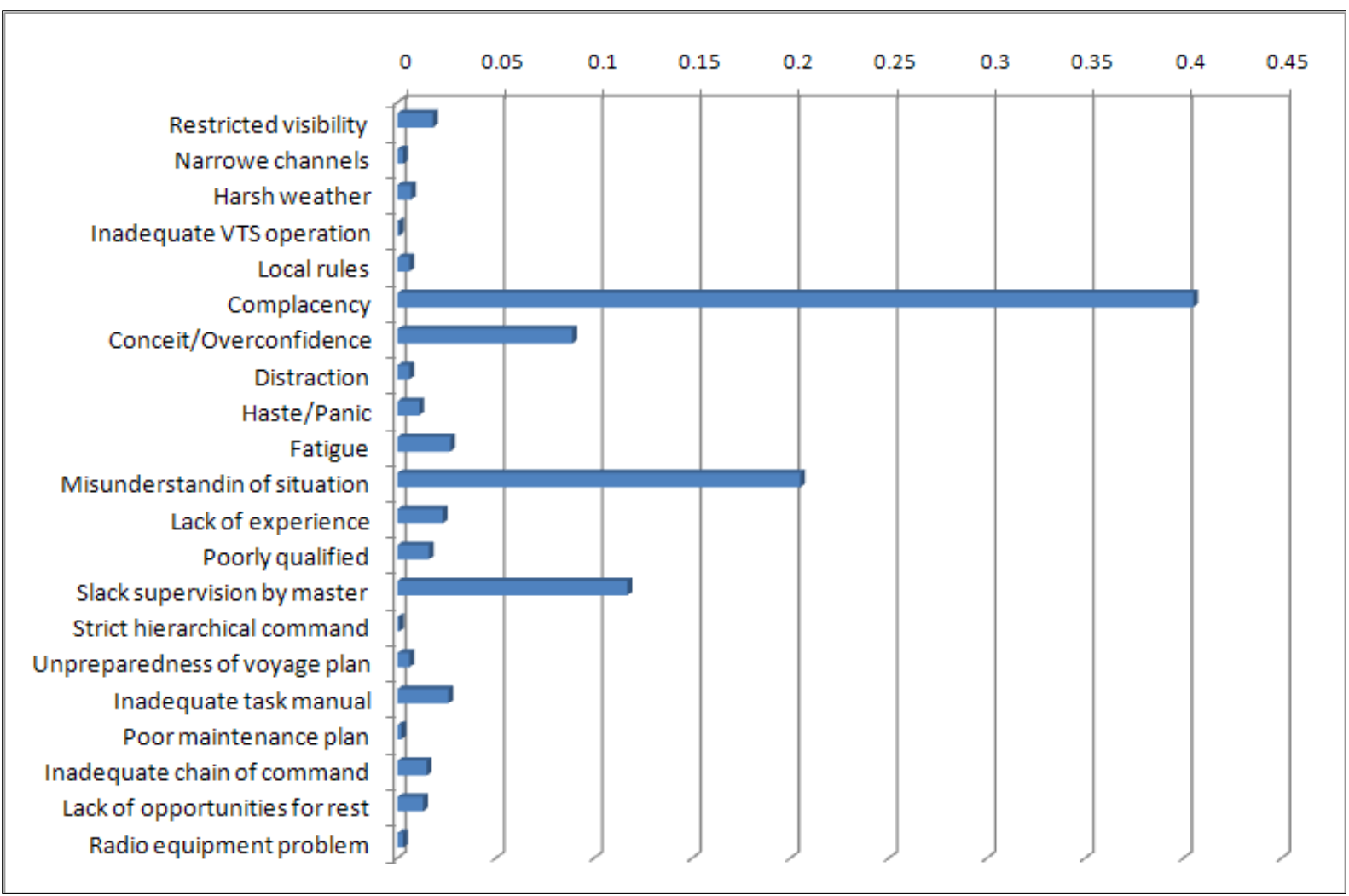

Fig. 5 Effect levels of underlying factors (onboard ship)

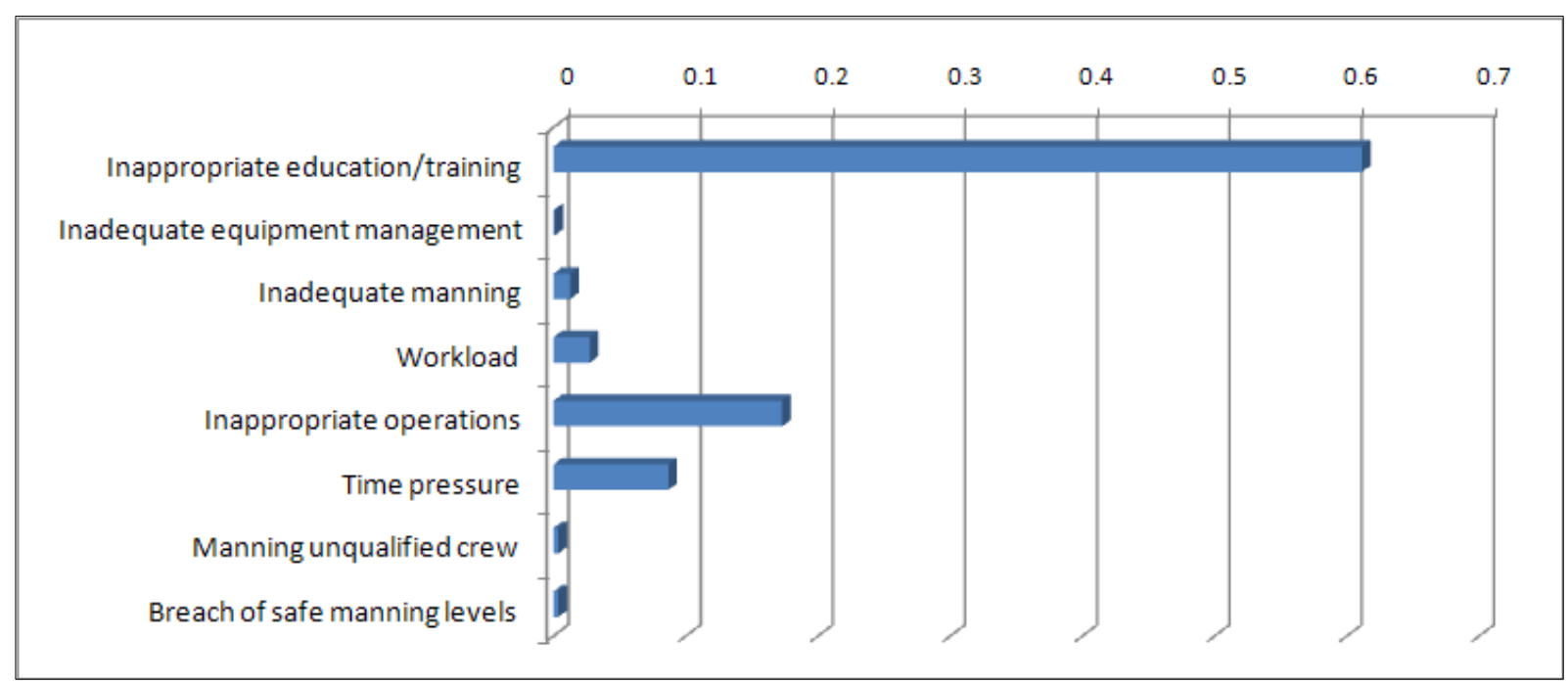

Fig. 6 Effect levels of underlying factors (shipping company)

\subsection{Degree of agreement between experts}

The risk-weight of those unsafe acts is ranked by the experts and the results of the ranking should be accompanied by a concordance coefficient ' $W$ ', indicating the level of agreement between the experts in order to enhance the transparency in the result(IMO, 2007). The concordance coefficient ' $\mathrm{W}$ ' may be calculated by the following formula:

$$
W=\frac{12 \sum_{i=1}^{i=I}\left[\sum_{j=1}^{j=J} X_{i j}-\frac{1}{2} J(I+1)\right]^{2}}{J^{2}\left(I^{3}-I\right)}
$$

Where,

$$
\begin{aligned}
& \mathrm{J}=\operatorname{expert}(1,2,3, \cdots, \mathrm{J}) \\
& \mathrm{I}=\operatorname{scenario}(1,2,3, \cdots, \mathrm{I}) \\
& \mathrm{W}=\operatorname{coefficient}(0 \leq \mathrm{W} \geq 1)
\end{aligned}
$$

The level of agreement is characterized in Table 3(IMO, 2007). 
Table 3 Concordance coefficients

\begin{tabular}{|c|c|c|}
\hline $\mathrm{W}$ & $>0.7$ & Good agreement \\
\hline $\mathrm{W}$ & $0.5-$ & Medium agreement \\
\hline $\mathrm{W}$ & 0.5 & Poor agreement \\
\hline
\end{tabular}

\section{Risk control options}

As shown by Fig. 7, in the case of collision accidents, underlying factors such as external factors, people factors, ship factors and shore-side management cause unsafe act to occur and, one or more of the unsafe acts cause the ship collision accident to occur.

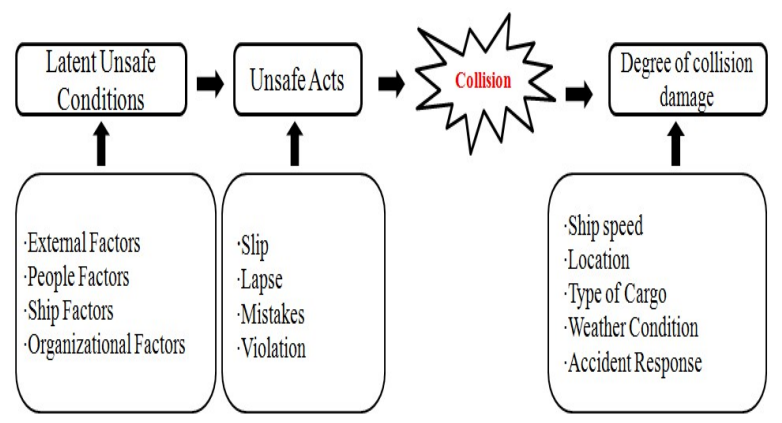

Fig. 7 Causes and consequences of collision accidents (focused on human error)

In addition, the consequences of a collision accident are subject to changes according to the ship speed, what sort of cargo she loaded, weather conditions, location of the collision accident occurred and how to deal with the accident.

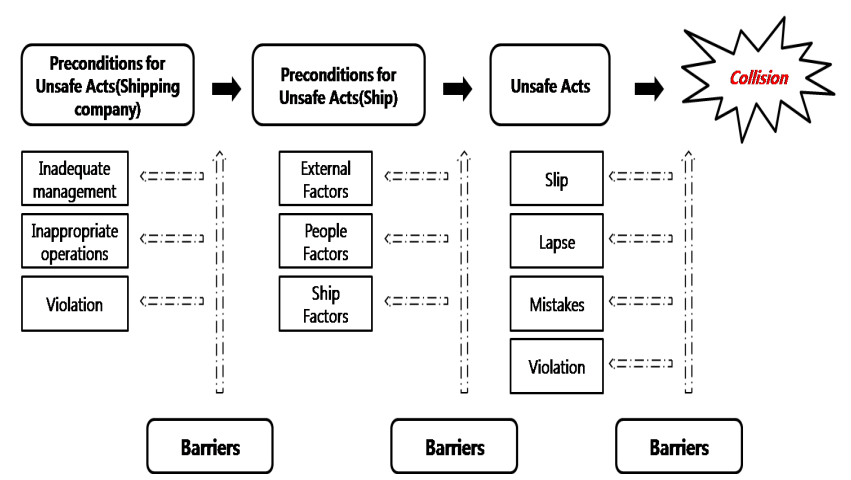

Fig. 8 Collision accident causal chains focused on human factors

For the study of towing vessel collision accident, causal chains focused on human factors are used as a method to assist the identification and the selection of Risk Control Measures and Options(see Fig. 8 below). The chain considers the entire "underlying cause to unsafe action to collision" sequence, with the aim of ensuring that all opportunities for preventing accident progression within this sequence are addressed.
Once those unsafe acts that affect ship collision accident and their underlying factors are identified, those human factors that need more attention should be selected. Then the Risk Control Measures and Options that could reduce the probability of occurrence of human error should be proposed. To achieve this, the techniques such as brain storming can be used by an expert group.

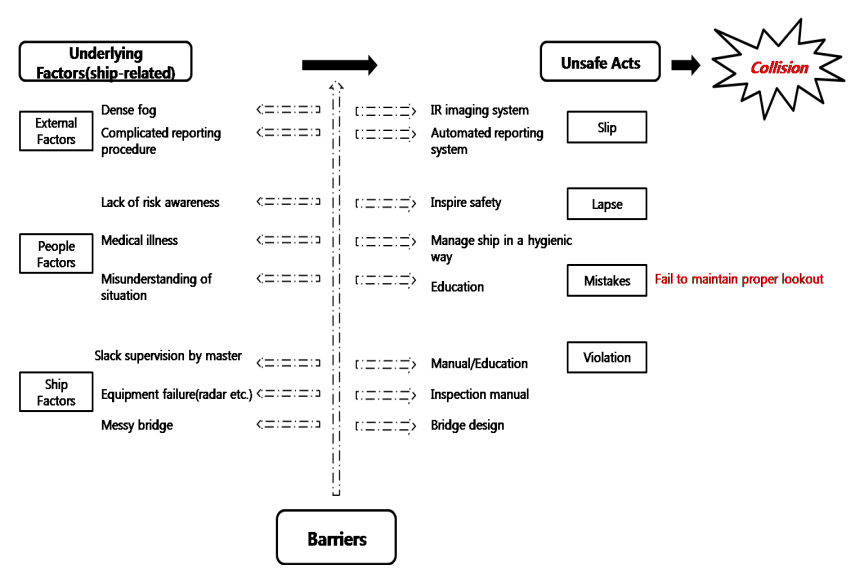

Fig. 9 Example of barriers(control measures)

Fig. 9 shows the example of ship-related underlying factors that could cause 'Fail to maintain proper lookout' and their example barriers. For instance, the underlying factors related to the External Factors could be a dense fog(environment) and a complicated reporting procedure when the ship arrives or leaves a port, or passes along the narrow straits or channels(Regulatory Influences). The barriers could be the installation of an IR(infrared) imaging system and the installation of an automated reporting system onboard.

\section{Conclusions}

This paper has presented a human error analysis methodology which comprises a cognitive process model, a human error analysis technique and a marine accident causal chains, and 18 towing vessel collision accidents from written accident reports were analyzed as a case study in order to verify the applicability of the proposed human error analysis methods to marine accidents. It should be noted that the underlying factors identified in this study would be quite different from those factors caused the 18 towing vessel collision accidents to occur in reality because this study was just carried out analyzing those written accident reports and this study was rather reactive than proactive in approach by the same reason. However, the human error analysis methods in this study can possibly be used as a tool to anticipate 
human related hazards rather than waiting for accidents to reveal them.

In order to reduce the probability of occurrence of human error and to mitigate the consequences of marine accidents, it is essential to develop a systematic marine accident investigation and/or analysis method which is relatively easy to learn and use, and to obtain more applications to marine accidents.

\section{Acknowledgement}

The contents of this paper are the results of the research project of MOERI/KORDI(Analysis of Tug-Barge Accident and its Prevention) and Ministry of Land, Transport and Maritime Affairs of Korea(Development of prevention and management technology for human-related marine accident).

\section{References}

[1] HFW (2002), 2nd International Workshop on Human Factors in Offshore Operations, RRS Engineering, www.rrseng.com.

[2] IMO (2000), Amendments to the Code for the Investigation of Marine Casualties and Incidents (Resolution A.849(20)), A 21/Res.884.

[3] IMO (2007), Consolidated text of the Guidelines for Formal Safety Assessment (FSA) for use in the IMO rule-making process (MSC/Circ.1023-MEPC/Circ.392), MSC 83/INF.2.

[4] IMO (2010), Vision, Principles and Goals, Accessed 29th January 2010, Available at: www.imo.org.

[5] Jong, J. Y. and Park, J. S. (1998), "A Study on the Analysis and the Quantification of Effect Level of Causal Factors in Tanker Casualties", Journal of the Korean Institute of Navigation, Vol. 22, No. 1, pp. 23-30.

[6] KMST (2008), Written Accident Report (2007.1.1 12.31), 11-1520595-000003-10.

[7] KMST (2009a), Written Accident Report (2008.1.1 12.31), ISSN 2005-7490.

[8] KMST (2009b), Statistics of marine accidents causes (2002 2006), Accessed 14th October 2009, Available at:http://www.kmst.go.kr/eng/cms/cms.asp?code=DE.

[9] Grech, M. R., Horberry, T.J., and Koester, T. (2008), Human Factors in the Maritime Domain, CRC Press, ISBN: 978-1-4200-4341-9.

[10] Reason, J. (1990), Human error, New York: Cambridge University Press.

[11] Ren, J., Jenkinson, I., Wang, J., Xu, D.L., and Yang, J.B.
(2008), "A methodology to model causal relationships on offshore safety assessment focusing on human and organizational factors”, Journal of Safety Research, vol. 39, pp. $87-100$.

[12] Shorrock, S.T. and Kirwan, B. (2002), "Development and application of a human error identification tool for air traffic control”, Applied Ergonomics, vol.33, pp.319-336.

Received 2 February 2010

Revised 11 March 2010

Accepted 16 March 2010 